\title{
A Cross-sectional Study on the Magnitude of undernutrition in Tuberculosis Patients in the Oromia Region of Ethiopia
}

\author{
Bedru Hussien' \\ Gobena Ameni ${ }^{2-4}$ \\ 'Department of Public Health, Madda \\ Walabu University, Goba Referral \\ Hospital, Robe Bale, Oromia, Ethiopia; \\ ${ }^{2}$ Aklilu Lemma Institute of Pathobiology, \\ Addis Ababa University, Addis Ababa, \\ Ethiopia; ${ }^{3}$ Department of Veterinary \\ Medicine, College of Agriculture and \\ Veterinary Medicine, United Arab \\ Emirates University, Al Ain, United Arab \\ Emirates; ${ }^{4}$ Department of Health Studies, \\ University of South Africa, Pretoria, \\ South Africa
}

\begin{abstract}
Purpose: To estimate the magnitude of undernutrition in tuberculosis (TB) patients and evaluate its association with selected sociodemographic and clinical characteristics of the patients.
\end{abstract}

Patients and Methods: A health facility-based cross-sectional design was used. Four hundred and fifty pulmonary TB (PTB) patients were recruited between September 2017 and August 2018. Data were collected by structured questionnaire and anthropometric measurements. Data were analyzed using SPSS 20. Descriptive statistics was used for the analysis and expression of the data. Regression model was used to determine the association between undernutrition and selected factors.

Results: The magnitude of underweight was 51.6\%, (95\%CI: 47.15-56.2). Binary logistic regression indicated that previous treatment with anti-TB (crude odds ratio, $\mathrm{COR}=1.68,95 \%$ CI: $1.08-2.63 ; p<0.023)$, duration of illness greater than two months $(\mathrm{COR}=2.11,95 \% \mathrm{CI}$ : $1.26-3.55, p<0.005)$, positive HIV serum status ( $\mathrm{COR}=3.83,95 \% \mathrm{CI}: 1.63-9.02, p<0.002)$ and history of resistance to any anti TB drug ( $\mathrm{COR}=2.76,95 \% \mathrm{CI}: 1.29-5.91, p<0.009)$ were associated with underweight. Multiple logistic regression analysis of the association of the aforementioned variables with undernutrition indicated that HIV positivity (adjusted odds ratio, $\mathrm{AOR}=0.26,95 \% \mathrm{CI}: 0.104-0.65, p<0.004)$ and resistance to any anti-TB drug $(\mathrm{AOR}=0.39,95 \% \mathrm{CI}: 0.173-0.90, p<0.026)$ were the associated factors.

Conclusion: A significant proportion of TB patients in the Oromia Region were malnourished. Therefore, nutritional counseling and nutritional supplementation are required for the effective treatment of TB patients in the Region.

Keywords: body mass index, undernutrition, tuberculosis, Oromia Region of Ethiopia

\section{Introduction}

The association between TB and undernutrition has long been known. TB and undernutrition interrelate in such a way that TB negatively affects the nutritional status of somebody and undernutrition exposes someone to active TB. ${ }^{1-3}$ Most individuals with active TB are in a consumed state worsening undernutrition and making them weak in defending against infections or allowing them to sustain easily the progression of subclinical cases to clinically apparent cases like latent TB to active TB. ${ }^{4,5}$ The patient may have poor appetite to eat perhaps as a result of fatigue or may not get enough to eat if they have few resources. ${ }^{4,6}$ It has also been found that malnourished TB patients have poor bioavailability (low proportion of a drug that can reach its target) of essential drugs like rifampicin. This can
Correspondence: Bedru Hussien Tel +251911997287

Email bedruplos1964@gmail.com 
contribute to treatment failure and development of multidrug resistance. There could also be higher risk of hepatotoxicity (which is a major side effect of TB therapy), poor adherence to medical treatment, delayed recovery and hence increased transmission rate, and higher mortality rates than well-nourished patients. ${ }^{7-9}$

Food and nutritional support as an incentive and enabler are employed by national TB control programs worldwide to make a difference in adherence to anti-TB drug treatment and sputum conversion period, cure and treatment completion rates, gain in body weight and body composition as well as performance status, or to modify associated risk factors for a better TB control program. ${ }^{10-}$ 12 Closer nutritional monitoring and earlier initiation of nutrition support (before the first two months of treatment are completed) should be considered particularly if the nutritional indicator is approaching the cutoff value for a diagnosis of severe-acute malnutrition. ${ }^{13}$

For appropriate intervention regarding undernutrition in TB patients for effective control program it is important to have updated information on the magnitude of the problem as well as associated factors. Although previous studies have shown the association between TB and undernutrition, additional studies can help in generating scientific information on the extent of undernutrition in TB patients in different geographic settings so that appropriate correction measures are taken in order to improve the outcome of TB treatment. The Oromia Region is one of the regional states of Ethiopia with the largest human population. Furthermore, similar to the other regions of the country, TB is prevalent in the Oromia Region. But little information is available on the extent of undernutrition in TB patients in the Oromia Region. The present study was formulated with the objective of investigating the magnitude of undernutrition in TB patients and associated risk factors in the Oromia Region and it forms part of a thesis that was done through the University of South Africa.

\section{Materials and Methods}

\section{Study Design and Setting}

A health facility (HF)-based cross-sectional design was used to conduct this study in the Oromia Region. This region is the largest state of the Federal Republic of Ethiopia with a population of about 40 million. With regard to health facilities, the region has a total of 108 hospitals, 1405 health centers and 7090 health posts. The health coverage of the region in terms of health centers and health posts were $93 \%$ and $94 \%$ in 2019, respectively. ${ }^{14}$ Data were collected during the period between September 2017 and August 2018.

\section{Study Population and Subjects}

Pulmonary TB (PTB) patients who are permanent residents of the Oromia Region, and individuals visiting health centers and hospitals located in the selected zones for ill health and were not on drug treatment for the current episode of TB were the study population.

\section{Sampling and Sample Size}

For sampling, the study zones and particular HFs were selected on the basis of convenience in terms of geographical accessibility and logistic capacity and patients were enrolled according to their presence for clinical consultation until the proportional numbers of people are obtained from each HF to totally recruit the estimated sample size of 450 . The criteria for recruitment of the study participates were, being a case of PTB diagnosed by a clinician according to the National TB and Leprosy Control Program Guideline ${ }^{15}$ and a permanent resident of the region.

\section{Data Collection Tool and Process}

A structured questionnaire was prepared in English and administered by the interviewer for data collection. Data were collected on sociodemographic characteristics and clinical history of the patient. The questionnaires were pretested on $25 \mathrm{~TB}$ patients outside the catchment areas of selected HFs and not included in the analysis. Modifications were made as necessary.

After informed consent, questionnaires were administered by trained data collectors in local languages. The data collectors were skilled laboratory technicians, nurses, and public health workers who can fluently speak, read and write local languages, Afan Oromo and Amharic.

Anthropometric measurements were taken. Weights were recorded using regularly calibrated beam balance ( \pm 100 g precision), with the patient wearing light clothing. Heights were recorded to the nearest centimeter with a stadiometer using standard procedures. Body mass index (BMI) was calculated as weight in kilograms divided by squared height in meters (Wt $(\mathrm{kg}) /$ $\mathrm{Ht}\left(\mathrm{m}^{2}\right)$ ). For those who were under the age of 18 years, the BMI-for-age percentiles were used for assessing nutritional status of boys and girls differently from BMI of adults. 


\section{Statistical Analysis}

The statistical analysis was performed using SPSS version 20. Descriptive statistics were used to depict the sociodemographic characteristics, clinical history, and nutritional status. The heights and weights measured were used to calculate the BMI (BMI=weight in $\mathrm{kg} /$ height in $\mathrm{m}^{2}$ ) at registration. A BMI of $\geq 18.5$ and $\leq 24.99 \mathrm{~kg} / \mathrm{m}^{2}$ was classified as normal, and undernutrition as BMI $<18.5 \mathrm{~kg} / \mathrm{m}^{2}$, overweight as BMI $\geq 25 \mathrm{~kg} / \mathrm{m}^{2}$. Different classes of malnutrition were also defined as follows: mild malnutrition, $\mathrm{BMI}=17.0-18.4 \mathrm{~kg} / \mathrm{m}^{2}$; moderate malnutrition, $\mathrm{BMI}=16.0-16.9 \mathrm{~kg} / \mathrm{m}^{2}$; severe malnutrition, BMI $<16.0 \mathrm{~kg} / \mathrm{m}^{2}{ }^{16-18}$ Bivariate and multiple logistic regression model analysis were used to test the statistical association between nutritional status and sociodemographic characteristics as well as clinical parameters. A $p$-value $<0.05$ was taken as statistically significant.

\section{Results}

\section{Sociodemographic and Clinical Characteristics of the Study Participants}

Of the 450 patients who were recruited into the study, 364 $(80.9 \%)$ of the study participants were within the age group of 18-45 years with the age range of 4-81 years and median age was 26. Male to female ratio was almost one to one and $180(40 \%)$ were from Arsi and East Shewa zones. About one-third of the patients were illiterate with very few first degree graduates. The clinical history of the patients revealed that nearly a quarter of them were previously treated as PTB patients for at least four weeks. There was delay in seeking medical treatment from modern HFs as concluded from the fact that about $70 \%$ sought modern treatment after four weeks of symptoms. One hundred and forty-eight (32.9\%) of them were users of khat or cigarette or alcohol beverages or combinations of these at least in the last one year prior to the interview. The TB-HIV co-infection rate was below $10 \%$. History of resistance to anti-TB drug was reported in $23(7.8 \%)$ of previously treated patients (Table 1).

\section{Estimation of Body Mass Index}

Two hundred and thirty-two $(51.6 \%, 95 \% \mathrm{CI}$ : 47.15-56.2) of all the subjects had fallen under the undernutrition range of BMI, and very few were found to be overweight (Table 2). The maximum, average, and minimum BMI of the patients were $27.11 \mathrm{~kg} / \mathrm{m}^{2}, 18.27 \mathrm{~kg} / \mathrm{m}^{2}$, and $12.5 \mathrm{~kg} /$ $\mathrm{m}^{2}$, respectively.

\section{Association Between Undernutrition and Different Factors}

Bivariate regression model analysis has shown that age group $<18$ years of age compared to age group 29-39; educational status of below secondary school compared to secondary school complete; and family size $>4$ compared to those with family size $\leq 4$ are associated with undernutrition $(p<0.25)$ as shown in Table 3. Multiple logistic regression analysis indicated that age group $<18$ was associated $\quad(\mathrm{AOR}=0.028, \quad 95 \% \mathrm{CI}: \quad 0.006-0.125) \quad$ with undernutrition.

In addition, the selected clinical parameters were statistically $(p<0.05)$ associated with undernutrition as computed by binary logistic regression model. Further analysis of the association of these risk factors with undernutrition using multiple logistic regression indicated that positive HIV serum status (adjusted odds ratio, AOR $=0.259,95 \%$ CI: 0.104-0.647) and history of resistance to anti-TB drug (AOR $=0.394,95 \% \mathrm{CI}: 0.173-0.897)$ were statistically associated with subnormal nutritional status (Table 4).

\section{Discussion}

The study involved 450 PTB patients in Oromia region of Ethiopia with the intention to determine the magnitude of undernutrition and the association of undernutrition with selected socio-demographic characteristics and clinical history.

The prevalence of undernutrition recorded by the present study was $51.6 \%$ and was a bit less than that reported from the Amhara Region of Ethiopia (57.17\%), ${ }^{19}$ but similarly in the beginning $50 \mathrm{~s}$ with that reported from the Adama Town of Ethiopia (53\%). ${ }^{20}$ The finding of systematic review and meta-analysis on the prevalence of undernutrition in TB patients in Ethiopia also reported a pooled prevalence of $50.8 \%(95 \% \mathrm{CI} \text { : } 43.97-57.63)^{21}$ and the report from Kenya, a neighboring country, as the institution-based study done in Turkana, showed the proportion of TB patients with undernutrition of $50.12 \%{ }^{22}$ which are also in agreement with the report of the present study. However, lower prevalence $(35.8 \%)$ of undernutrition was reported from Burkina $\mathrm{Faso}^{23}$ while a significantly higher prevalence (85\%) was reported from central rural India. ${ }^{24}$ This could possibly be due to differences in socioeconomic standards among others between the populations.

According to this study, those previously treated and who had duration of illness $>1$ month before starting 
Table I Sociodemographic and Clinical Characteristics of the Study Participants, Oromia, 2020

\begin{tabular}{|c|c|c|}
\hline \multicolumn{2}{|l|}{ Characteristics } & \multirow{2}{*}{$\begin{array}{l}\mathbf{N}(\%) \\
52(11.6)\end{array}$} \\
\hline Age (years) & $<18$ & \\
\hline & $18-28$ & $203(45.1)$ \\
\hline & $29-39$ & $106(23.6)$ \\
\hline & $40-45$ & $55(12.2)$ \\
\hline & $>45$ & $34(7.6)$ \\
\hline \multirow[t]{2}{*}{ Sex } & Male & $240(53.3)$ \\
\hline & Female & $210(46.7)$ \\
\hline \multirow[t]{9}{*}{ Address (zones) } & North Shewa & $37(8.2)$ \\
\hline & South West Shewa & $28(6.2)$ \\
\hline & East Shewa & $92(20.4)$ \\
\hline & Arsi & $88(19.6)$ \\
\hline & West Arsi & $24(5.3)$ \\
\hline & Bale & $64(14.2)$ \\
\hline & Guji & $60(13.3)$ \\
\hline & Borena & $25(5.6)$ \\
\hline & West Harerge & $32(7.1)$ \\
\hline \multirow[t]{5}{*}{ Education } & Cannot read and write & $169(37.6)$ \\
\hline & Read and write & $88(19.6)$ \\
\hline & Elementary & $146(32.4)$ \\
\hline & Secondary & $31(6.9)$ \\
\hline & College and above & $16(3.6)$ \\
\hline \multirow[t]{3}{*}{ Family size } & Lives alone & $10(2.2)$ \\
\hline & $1-4$ & $298(66.2)$ \\
\hline & $>4$ & $142(31.6)$ \\
\hline \multirow[t]{2}{*}{ Category of tuberculosis treatment history } & New & $343(76.2)$ \\
\hline & Previously treated & $107(23.8)$ \\
\hline \multirow[t]{3}{*}{ History of anti-TB drug resistance $(\mathrm{N}=107)$} & No & $58(54.2)$ \\
\hline & Yes & $23(2 \mid .5)$ \\
\hline & Unknown & $26(24.3)$ \\
\hline \multirow[t]{3}{*}{ Duration of illness before medical treatment } & $<1$ month & $137(30.4)$ \\
\hline & $\mathrm{I}-2$ months & $225(50.0)$ \\
\hline & $>2$ months & $88(19.6)$ \\
\hline \multirow[t]{2}{*}{ Currently smoking } & No & $421(93.6)$ \\
\hline & Yes & $29(6.4)$ \\
\hline \multirow[t]{2}{*}{ Currently chewing khat } & No & $382(84.9)$ \\
\hline & Yes & $68(15.1)$ \\
\hline \multirow[t]{2}{*}{ Drink alcohol beverages } & No & $399(88.7)$ \\
\hline & Yes & $51(11.3)$ \\
\hline \multirow[t]{3}{*}{ HIV serum status } & Negative & $404(89.8)$ \\
\hline & Positive & $34(7.6)$ \\
\hline & Unknown & $12(2.6)$ \\
\hline
\end{tabular}


Table 2 Distribution of Body Mass Index of the Study Participants, Oromia, 2020

\begin{tabular}{|l|l|l|l|}
\hline \multicolumn{2}{|l|}{ Category of BMI $\mathbf{( k g / \mathbf { m } ^ { 2 } )}$} & $\mathbf{N}(\%)$ & $95 \%$ Confidence Interval \\
\hline$<16.0$ & Severe undernutrition & $40(8.9)$ & $6.4-11.6$ \\
\hline $16.0-16.99$ & Moderate undernutrition & $52(11.6)$ & $8.9-14.9$ \\
\hline $17.0-18.49$ & Mild undernutrition & $140(31.1)$ & $26.9-35.3$ \\
\hline $18.5-24.99$ & Normal & $213(47.3)$ & $42.9-51.8$ \\
\hline$>25$ & Overweight & $5(1.1)$ & $0.2-2.0$ \\
\hline & Total & 450 & \\
\hline
\end{tabular}

treatment have shown a tendency to become undernourished probably because of the longstanding and recurrent existence of infection that negatively affects dietary intake, and overall metabolism whereby lipolysis and proteolysis may cause surplus anabolic activities. ${ }^{25}$ Patients with positive HIV serum status have also shown greater tendency to become undernourished; this could be due to additional stress of infection and also possibility of opportunistic diseases on top of the underlying common factors with HIV negative TB cases.

In general, it is an established fact that undernutrition has been found to be associated with adverse TB treatment outcomes and its presence at the initial diagnosis of active TB has been reported to be a predictor of increased risk of death and TB relapse. ${ }^{5,26-29}$ In support of this fact, the study done in Beira (Mozambique) had shown that low BMI, among other social determinants including: being male, low socioeconomic status (education and income), and HIV serum positivity increases the likelihood of therapy failure in newly diagnosed PTB patients. ${ }^{30}$ Studies have also indicated that undernutrition may affect responses to BCG vaccination which is an important approach in the prevention of active TB in addition to impairment of innate and adaptive immune responses needed to control Mycobacterium tuberculosis infection. ${ }^{31}$ It is also possible to extrapolate that malnutrition could have a role in the development of drug resistance which could be due to impaired immunity as a result of poor nutrition that may allow organisms of $M$. tuberculosis to stand against the effect of a drug or drugs.

Table 3 Association of Sociodemographic Characteristics of TB Patients with Undernutrition in TB Patients, Oromia, 2020 (N=445)

\begin{tabular}{|c|c|c|c|c|c|c|c|}
\hline \multicolumn{2}{|c|}{ Characteristics } & \multicolumn{2}{|c|}{ Nutritional Status } & \multirow[t]{2}{*}{ COR $(95 \% \mathrm{Cl})$} & \multirow[t]{2}{*}{$p$-value } & \multirow[t]{2}{*}{ AOR(95\% Cl) } & \multirow[t]{2}{*}{$p$-value } \\
\hline & & $<\mathbf{N}$ & $\mathbf{N}$ & & & & \\
\hline Age group & $\begin{array}{l}<18 \\
18-28 \\
29-39 \\
40-50 \\
>50\end{array}$ & $\begin{array}{l}50 \\
92 \\
47 \\
24 \\
19\end{array}$ & $\begin{array}{l}2 \\
108 \\
58 \\
31 \\
14\end{array}$ & $\begin{array}{l}0.032(0.007-0.140) \\
0.95 \mathrm{I}(0.952-0.529) \\
\mathrm{I} \\
\mathrm{I} .047(0.542-2.020) \\
0.597(0.27 \mathrm{I}-1.316)\end{array}$ & $\begin{array}{l}0.000 \\
0.837 \\
0.892 \\
0.201\end{array}$ & $\begin{array}{l}0.028(0.006-0.125) \\
0.893(0.547-1.468) \\
\mathrm{I} \\
\mathrm{I} .03 \mathrm{I}(0.530-2.007) \\
0.624(0.280-1.388)\end{array}$ & $\begin{array}{l}0.000 \\
0.651 \\
0.928 \\
0.247\end{array}$ \\
\hline Education & $\begin{array}{l}\text { Illiterate } \\
\text { Read and write } \\
\text { Elementary } \\
\text { Secondary } \\
\text { College + }\end{array}$ & $\begin{array}{l}86 \\
46 \\
81 \\
13 \\
6\end{array}$ & $\begin{array}{l}81 \\
42 \\
63 \\
18 \\
9\end{array}$ & $\begin{array}{l}0.680(0.3 \mid 3-1.477) \\
0.659(0.288-1.508) \\
0.562(0.256-1.232) \\
I \\
I .083(0.309-3.802)\end{array}$ & $\begin{array}{l}0.330 \\
0.324 \\
0.150 \\
0.901\end{array}$ & $\begin{array}{l}0.730(0.327-1.630) \\
0.786(0.337-1.835) \\
0.910(0.404-2.05 \mathrm{I}) \\
\mathrm{I} \\
\mathrm{I} .230(0.334-4.533)\end{array}$ & $\begin{array}{l}0.442 \\
0.578 \\
0.821 \\
\\
0.756\end{array}$ \\
\hline Family size & $\begin{array}{l}\text { Lives alone } \\
\mathrm{I}-4 \\
>4\end{array}$ & $\begin{array}{l}6 \\
145 \\
81\end{array}$ & $\begin{array}{l}4 \\
148 \\
61\end{array}$ & $\begin{array}{l}0.653(0.18 I-2.363) \\
\mathrm{I} \\
0.738(0.493-1.105)\end{array}$ & $\begin{array}{l}0.516 \\
0.140\end{array}$ & $\begin{array}{l}0.53 \mathrm{I}(0.142-1.983) \\
\text { I } \\
\text { I.I } 25(0.7 \mid 7-1.767)\end{array}$ & $\begin{array}{l}0.347 \\
0.608\end{array}$ \\
\hline
\end{tabular}

Abbreviations: $<\mathrm{N}$, undernutrition; $\mathrm{Cl}$, confidence interval. 
Table 4 Association of Clinical History with Undernutrition in TB Patients, Oromia, 2020

\begin{tabular}{|c|c|c|c|c|c|c|c|}
\hline \multicolumn{2}{|c|}{ Characteristics } & \multicolumn{2}{|c|}{ Nutritional Status } & \multirow[t]{2}{*}{ COR $(95 \% \mathrm{Cl})$} & \multirow[t]{2}{*}{$p$-value } & \multirow[t]{2}{*}{ AOR $(95 \% \mathrm{Cl})$} & \multirow[t]{2}{*}{$p$-value } \\
\hline & & $<\mathbf{N}$ & Normal & & & & \\
\hline \multirow[t]{2}{*}{ Treat. Cat } & New & 167 & 173 & I & & & \\
\hline & Repeat & 65 & 40 & $1.683(1.076-2.634)$ & 0.023 & I.4I (0.628-2.075) & 0.665 \\
\hline \multirow[t]{3}{*}{ Dol } & $<1$ month & 68 & 69 & 1 & & & \\
\hline & $\mathrm{I}-2$ months & 108 & 115 & $1.994(1.141-3.487)$ & 0.015 & $1.042(0.648-1.675)$ & 0.865 \\
\hline & $>2$ months & 57 & 29 & $2.112(1.257-3.549)$ & 0.005 & $0.579(0.29 I-1.155)$ & 0.121 \\
\hline \multirow[t]{2}{*}{ HIV status } & Negative & 200 & 199 & I & & & \\
\hline & Positive & 27 & 7 & 3.838 (1.634-9.017) & 0.002 & $0.259(0.104-0.647)$ & 0.004 \\
\hline \multirow[t]{2}{*}{ Khat } & No & 200 & 179 & I & & & \\
\hline & Yes & 32 & 34 & $0.842(0.499-1.42 I)$ & 0.520 & $1.229(0.618-2.444)$ & 0.556 \\
\hline \multirow[t]{2}{*}{ Alcohol } & No & 207 & 188 & I & & & \\
\hline & Yes & 25 & 25 & $0.908(0.504-1.636)$ & 0.748 & $1.255(0.6 \mid 2-2.57)$ & 0.535 \\
\hline \multirow[t]{2}{*}{ Cigarette } & No & 217 & 199 & I & & & \\
\hline & Yes & 15 & 14 & $0.983(0.463-2.087)$ & 0.963 & $1.073(0.397-2.897)$ & 0.889 \\
\hline \multirow[t]{2}{*}{ History of DR } & NR & 166 & 183 & I & & & \\
\hline & $\mathrm{R}$ & 25 & 10 & $2.756(1.285-5.910)$ & 0.009 & $0.394[0.173-0.897)$ & 0.026 \\
\hline
\end{tabular}

Abbreviations: Dol, Duration of illness; DR, Drug Resistance; NR, No resistance; R, Resistance.

It is not only the socioeconomic support that is observed to be in deficit, but also the nutritional assessment and counseling were not as they are supposed to be as manifested by missing information regarding nutritional status of previous TB patients and absences of nutritional counseling for newly presenting patients during data collection. In support of this fact, the qualitative study done in Tigray Region (a preprint of manuscript) has indicated the existence of related problems and that factors associated with these inappropriate conditions in regard to nutrition include: lack of supportive supervision, shortage of staff, phasing out of supporting partners; lack of commitment from health workers; and very low economic status of patients, sharing and selling of provided supplies, and defaulting from treatment. ${ }^{32}$

In line with the socioeconomic aspect of $\mathrm{TB}$, people with TB commonly face reduction of income in two ways. That is, they can become too sick to work and get income; or, they or their families have to cover other expenses related to the treatment even if diagnosis and drug treatment is free. Therefore, they economically go downhill. ${ }^{8,33-35}$ Out of the 450 TB patients participated in the study only 30 (7.8\%) could possibly benefit from the existing nutritional support system because of their positive HIV status.
Supplementary feeding in food insecure and vulnerable people is proven to be associated with reduced number of patients dropping out, increased recovery rate, increased treatment completion and sputum conversion rate during active TB. Food and nutritional support optimize the nutritional value and adequacy of the diet, improve quality of life and improve various health parameters of disadvantaged families. ${ }^{10,36-40}$

The socioeconomic situation of TB patients demands multisectoral action to address the social and economic determinants including material support. This can be food or financial support like meals, food baskets, food supplements, food vouchers, transport subsidies, living allowance, housing incentives, or financial bonus as recommended by the WHO in order to access health services and, possibly, to mitigate consequences of income loss related to the disease and consequences of TB as part of the strategies of ending TB. ${ }^{13,41}$

\section{Conclusion}

Quite a significant proportion of TB patients in Oromia region is undernourished. Medical treatment alone is not adequate for effective TB control program. Therefore, nutritional assessment, counseling and need based socioeconomic support for TB patients demand attention of the program holders. 


\section{Abbreviations}

BMI, body mass index; HF, health facility; PTB, pulmonary tuberculosis; $\mathrm{TB}$, tuberculosis.

\section{Data Sharing Statement}

The datasets used and/or analyzed during the current study are available from the corresponding author on reasonable request.

\section{Ethics Approval and Consent to Participate}

Ethical clearance was obtained from Health Studies Higher Degree Committee of University of South Africa (Ref No: REC-012714-039, HSHDC/454/2015). The Oromia Regional Health Bureau gave permission and has written a letter of support to respective Health Departments. The purpose of the study was explained to the study participants and written consent was obtained from each. For those aged less than 18 years as well, written informed consent was obtained from their parents/legal guardians. All in accordance with the Declaration of Helsinki. ${ }^{42}$

\section{Acknowledgment}

The researchers are indebted to Madda Walabu University for its financial support to partially cover personnel costs and transportation. Oromia Health Bureau and selected HFs for their permission to use their facilities. We are also grateful to staff members of the health facilities and study participants for their cooperation.

\section{Disclosure}

The authors report no conflicts of interest in this work.

\section{References}

1. Lönnroth K, Williams BG, Cegielski P, Dye C. A consistent loglinear relationship between tuberculosis incidence and body mass index. Int $J$ Epidemiol. 2010;39:149-155. doi:10.1093/ije/ dyp308pmid:19820104

2. Kant S, Gupta H, Ahluwalia S. Significance of nutrition in pulmonary tuberculosis. Crit Rev Food Sci Nutr. 2015;55(7):7955-7963. doi:10.1080/10408398.2012.679500

3. Annabel Kanabus, GHE. Food and TB. TBFACT.ORG information about tuberculosis. [s.a.]. Available from: https://tbfacts.org/food.tb/.

4. Brooks JA. Management of patients with chest and lower respiratory disorders, in Bruner and Suddarth's textbook of medical-surgical nursing, 12th edn, 1(1), edited by Hilarie Surrena. Lippincott. 2010;551-600.

5. World Health Organization. Guideline: Nutritional Care and Support for Patients with Tuberculosis. Geneva, Switzerland: WHO; 2013.
6. Grobler L, Nagpal S, Sudarsanam TD, Sinclair D. Nutritional supplements for people being treated for active tuberculosis. Cochrane Database Syst Rev. 2016;6:CD006086. doi:10.1002/14651858. CD006086.pub4/abstract

7. Lutge E, Wiysonge C, Knight S, Sinclair D, Volmink J. Incentives and enablers to improve adherence in tuberculosis. Cochrane Database Syst Rev. 2015;2015(9): CD007952. doi:10.1002/ 14651858.CD007952.pub3

8. Pande JN, Singh SP, Khilnani GC, Khilnani S, Tandon RK. Risk factors for hepatotoxicity from antituberculosis drugs: a case-control study. Thorax. 1996;51(2):132-136. doi:10.1136/thx.51.2.132

9. Ramachandran G, Kumar AKH, Bhavani PK, et al. Age, nutritional status and INH acetylator status affect pharmacokinetics of anti-tuberculosis drugs in children. Int $J$ Tuberc Lung Dis. 2013;17:800-806. doi:10.5588/ijtld.12.0628

10. Chua AP, Lim LK, Ng H, Chee CB, Wang YT. Outcome of a grocery voucher incentive scheme for low-income tuberculosis patients on directly observed therapy in Singapore. Singapore Med J. 2015;56 (5):274-279. doi:10.11622/smedj.2015054

11. Gupta KB, Gupta R, Atreja A, Verma M, Vishvkarma S. Tuberculosis and nutrition. Lung India. 2009;26(1):9-16. doi:10.4103/09702113.45198

12. Oliver M. What's the link between TB and nutrition? Results UK; 2013. Available from: http://blog.results.org.uk/. Accessed February $1,2017$.

13. World Health Organization. Nutritional Care and Support for Patients with Tuberculosis. E-Library of Evidence for Nutrition Actions. Geneva: WHO; 2017.

14. Oromia Health Bureau. Available from:https://orhb.gov.et/index.php. Accessed June 102021.

15. Federal Ministry of Health. Tuberculosis, Leprosy, and TB/HIV Prevention and Control Program Manual. 4th. Addis Ababa, Ethiopia; 2008:30.

16. NHANES. Anthropometric Procedure Manuals. Vol. 1. United State of America: National Health and Nutrition Examination Survey; 2007.

17. World Health Organization. Nutritional Landscape Information System. Geneva: WHO; 2010:1-51.

18. World Health Organization. BMI Classification. Geneva: WHO; 2019. Available from http://www.apps.who.int/bmi. Accessed October 25, 2020.

19. Feleke BE, Feleke TE, Biadglegne F. Nutritional status of tuberculosis patients, a comparative cross-sectional study. BMC Pulm Med. 2019;19(1:182. doi:10.1186/s12890-019-0953-0

20. Guadie FF, Assaminew B. Assessment of nutritional status and associated factors among adult TB patients on directly observed treatment of short course in health facilities at Adama town, East shewa zone, Ethiopia. Scholar Pract J. 2016.

21. Wondmieneh A, Gedefaw G, Getie A, Demis A. Prevalence of undernutrition among adult tuberculosis patients in Ethiopia: a systematic review and meta-analysis. J Clin Tuberc Other Mycobact Dis. 2020;22:100211.

22. Nthiga I, Mbithe D, Mugendi BJ, Wambui T. The nutritional status of pulmonary tuberculosis patients aged 25-44 years attending tuberculosis clinic at Lodwar County and referral hospital, Turkana County, Kenya. Murang'a Univ Technol Inst Repstry. 2017;2(1):119-122.

23. Musuenge BB, Poda GG, Chen PC. Nutritional status of patients with tuberculosis and associated factors in the health centre region of Burkina Faso. Nutrients. 2020;12(9):2540. doi:10.3390/ nu12092540

24. Bhargava A, Chatterjee M, Jain Y, et al. Nutritional status of adult patients with pulmonary tuberculosis in rural central India and its association with mortality. PLoS One. 2013;8(10):e77979. doi:10.1371/journal.pone.0077979 
25. Paranandi A, Wanke C. Tuberculosis infection and nutrition. In: de Pee S, Taren D, Bloem M. (eds). Nutrition and Health in a Developing World. Nutrition and Health. Humana Press, Cham; 2017:437-447. Available from: https://link.springer.com/chapter/10. 1007/978-3-319-43739-2_19\#citeas. Accessed June 10, 2021

26. Alam I, Larbi A, Pawelec G. Nutritional status influences peripheral immune cell phenotypes in healthy men in rural Pakistan. PMC. 2012;9:1-10. PMid: 22863368. doi:10.1186/1742-4933-9-16

27. Hood ML. A narrative review of recent progress in understanding the relationship between tuberculosis and protein energy malnutrition. Eur J Clin Nutr. 2013;67(11):1122-1128. doi:10.1038/ejen.2013.143

28. Wingfield T, Boccia D, Tovar M, et al. Defining catastrophic costs and comparing their importance for adverse tuberculosis outcome with multi-drug resistance: a prospective cohort study, Peru. PLOS Med. 2014;11(7):e1001675. doi:10.1371/journal.pmed.1001675

29. Seid G, Ayele M. Undernutrition and mortality among adult tuberculosis patients in Addis Ababa, Ethiopia. Adv Prev Med. 2020;27:2020.

30. Pizzol D, Veronese N, Marotta C, et al. Predictors of therapy failure in newly diagnosed pulmonary tuberculosis cases in Beira, Mozambique. BMC Res Notes. 2018;11(1):1-6. doi:10.1186/s13104018-3209-9

31. Sinha P, Davis J, Saag L, et al. Undernutrition and tuberculosis: public health implications. J Infect Dis. 2019;219(9):1356-1363. doi:10.1093/infdis/jiy675

32. Degefa MG, Bezabih AM, Kahsay ZH, Belachew AB. Barriers and facilitators of nutrition assessment, counseling and support for Tuberculosis patients: a qualitative study. Res Square. Preprint manuscript. doi:10.21203/rs.3.rs-96716/v1

33. Lönnroth K, Glaziou P, Weil D, Floyd K, Uplekar M, Raviglione M. Beyond UHC: monitoring health and social protection coverage in the context of tuberculosis care and prevention. PLOS Med. 2014;11 (9):e1001693. doi:10.1371/journal.pmed.1001693
34. Mauch V, Bonsu F, Gyapong M, et al. Free tuberculosis diagnosis and treatment are not enough: patient cost evidence from three continents. Int J Tuberc Lung Dis. 2013;17(3):381-387. doi:10.5588/ijtld.12.0368

35. Tanimura T, Jaramillo E, Weil D, Raviglione M, Lönnroth K. Financial burden for tuberculosis patients in low-and middle-income countries: a systematic review. Eur Respir J. 2014;43:1763-1775. doi:10.1183/09031936.00193413

36. Koethe JR, Von Reyn CF. Protein-calorie malnutrition, macronutrient supplements, and tuberculosis. Int J Tuberc Lung Dis. 2016;20 (7):857-863. doi:10.5588/ijtld.15.0936

37. Lai -H-H, Lai Y-J, Yen Y-F, Dowdy DW. Association of body mass index with timing of death during tuberculosis treatment. PLoS One. 2017;12(1):e0170104. doi:10.1371/journal.pone.0170104

38. Mansour O, Masini EO, Kim BS, Kamene M, Githiomi MM, Hanson CL. Impact of a national nutritional support programme on loss to follow-up after tuberculosis diagnosis in Kenya. Int J Tuberc Lung Dis. 2018;22(6):649-654. doi:10.5588/ijtld.17.0537

39. Visser J, McLachlan MH, Maayan N, Garner P. Community-based supplementary feeding for food insecure, vulnerable and malnourished populations-an overview of systematic reviews. Cochrane Database Syst Rev. 2018;11.

40. Rocha C, Montoya R, Zevallos K, et al. The innovative socio-economic interventions against tuberculosis (ISIAT) project: an operational assessment. Int $J$ Tuberc Lung Dis. 2011;15 (6):50-57. doi:10.5588/ijtld.10.0447

41. World Health Organization. End TB Strategy. Geneva: WHO; 2016.

42. World Medical Association. World Medical Association declaration of Helsinki: ethical principles for medical research involving human subjects. JAMA. 2013;310(20):2191-2194. PMID: 24141714. doi:10.1001/jama.2013.281053
Journal of Multidisciplinary Healthcare

\section{Publish your work in this journal}

The Journal of Multidisciplinary Healthcare is an international, peerreviewed open-access journal that aims to represent and publish research in healthcare areas delivered by practitioners of different disciplines. This includes studies and reviews conducted by multidisciplinary teams as well as research which evaluates the results or conduct of such teams or healthcare processes in general. The journal

\section{Dovepress}

covers a very wide range of areas and welcomes submissions from practitioners at all levels, from all over the world. The manuscript management system is completely online and includes a very quick and fair peer-review system. Visit http://www.dovepress.com/testimonials. php to read real quotes from published authors. 